\title{
Distribution of perfluorinated compounds in Lake Taihu (China): Impact to human health and water standards
}

\author{
Gang Pan ${ }^{\mathrm{a}, *, 1}$, Qin Zhou ${ }^{\mathrm{a}, 1}$, Xuan Luan ${ }^{\mathrm{a}}$, Q. Shiang Fu ${ }^{\mathrm{b}}$ \\ a Research Center for Eco-Environmental Sciences, Chinese Academy of Sciences, Beijing 100085, China \\ b School of Environmental Science and Technology, Dalian University of Technology, Dalian, China
}

\section{H I G H L I G H T S}

- Distribution of seven PFCs in water/sediment of Lake Taihu is investigated.

- Sediment is an internal buffering reservoir of PFOS.

- PFOS level has health risk when bioaccumulation \& sediment reservoir are considered.

- A study for developing drinking water standards of PFCs in freshwater.

\section{A R T I C L E I N F O}

\section{Article history:}

Received 1 August 2013

Received in revised form 31 October 2013

Accepted 19 November 2013

Available online 8 December 2013

\section{Keywords:}

Perfluorooctane sulfonate (PFOS)

Perfluorinated compounds (PFCs)

Health risks

Buffering reservoir

Water standards

\begin{abstract}
A B S T R A C T
The distribution in water and sediment, the sources/sinks and the risk of perfluorinated compounds (PFCs) in Lake Taihu, China were investigated. The total PFCs concentration was 164 to $299 \mathrm{ng} \mathrm{L}^{-1}$ in water and 5.8 to $35 \mathrm{ng} \mathrm{g}^{-1}(\mathrm{dw})$ in sediment. The highest concentrations of perfluorooctane sulfonate (PFOS) and perfluorooctanoate (PFOA) in water were $29.2 \mathrm{ng} \mathrm{L}^{-1}$ and $136 \mathrm{ng} \mathrm{L}^{-1}$. PFOS was largely associated with sediment, whereas short chain PFCs predominated in water. The partition coefficient $\left(K_{\mathrm{d}}\right)$ was positively correlated with the organic carbon fraction $\left(f_{\text {oc }}\right)$ for PFOS but not for the other PFCs. The organic carbon normalized partition coefficient $\left(K_{\mathrm{oc}}\right)$ increased by $0.51 \log$ units for each additional $\mathrm{CF}_{2}$ moiety from perfluoro-butanesulfonate (PFBS) to PFOS. For the same chain length but different functional groups, the log $K_{\text {oc }}$ of PFOS was 1.35 units higher than PFOA. PFOS exhibited the highest affinity for sediment through the partition mechanism, and $f_{\text {oc }}$ affected the sediment as a sink of PFOS. Although there was no immediate health impact by the intake of the water alone, the consumption of aquatic products may cause potential health risks for animals/humans on the time scale of months to years. The relationship between the concentration, water-sediment distribution, bioaccumulation and toxicity should be considered in determining the water standards of PFCs.
\end{abstract}

(c) 2013 Elsevier B.V. All rights reserved.

\section{Introduction}

Perfluorooctane sulfonate (PFOS) and perfluorooctanoate (PFOA), as typical perfluorinated compounds (PFCs), have attracted increased regulatory scrutiny because of their resistance to degradation, tendency toward bioaccumulation, and growing evidence of toxicity in animal studies (Newsted et al., 2005; Yamashita et al., 2005). The intake of drinking water is an important exposure pathway of PFOS and PFOA for human beings (Mak et al., 2009). Provisional safe values in drinking water of $7 \mu \mathrm{g} \mathrm{L}{ }^{-1}$ for PFOA and $1 \mu \mathrm{g} \mathrm{L} \mathrm{L}^{-1}$ for PFOS were recommended in Minnesota in 2005 (3M, 2005). Consequently, several states have

Abbreviations: RD, reference dose; HR, hazard ratio; ADC, estimated average daily consumptions; BAF, bioaccumulation factor; ET, Emergent Time.

* Corresponding author. Tel.: +86 10 62849686; fax: +8610 62943436.

E-mail address: gpan@rcees.ac.cn (G. Pan).

1 These authors should be regarded as co-first authors. moved forward to develop safe concentrations for PFOA and PFOS. A value of $0.2 \mu \mathrm{g} \mathrm{L}^{-1}$ for PFOS and $0.4 \mu \mathrm{g} \mathrm{L}^{-1}$ for PFOA in drinking water was published by the Environmental Protection Agency of USA. A drinking water instructional value of $0.04 \mu \mathrm{g} \mathrm{L}{ }^{-1}$ for PFOA was established in New Jersey (http://www.serdp-estcp.org/FundingOpportunities/SERDP-Solicitations/Core-SONs-FY14). These standards are very different, which will greatly affect the management and effectiveness in protecting the public health. In fact, there are no drinking water standards for PFCs in most countries of the world, including China. After PFOS was listed as a new member of the persistent organic pollutants (POPs) under the Stockholm Convention in 2009, there was a strong and urgent need for strategic baseline studies that are prerequisite for a science-based and cost-effective water standard.

Although many field studies focused on reporting the concentration levels of PFOS/PFOA, little research has been performed on the longterm impact based on the survey studies. The "safe water" may not 
actually be safe when bioaccumulation. This effect may greatly vary depending on the toxicity and bioaccumulation factors of the different PFCs, which is not well understood. Lake Taihu $\left(2425 \mathrm{~km}^{2}\right)$ is the third largest freshwater lake in China and has a very broad impact, affecting more than 34 million people (http://baike.baidu.com/view/ 1596.htm). Most environmental studies on this lake have focused on the harmful cyanobacterial blooms (Paerl and Huisman, 2008; Pan et al., 2006). Little attention has been paid to PFOS and PFOA in this important freshwater system (Qiu et al., 2010; Yang et al., 2011). However, the issue of PFCs in Lake Taihu has attracted international attention (Davies, 2012). In addition, some short chain substitutes of PFOS exhibit significant toxicity to certain species (Rosal et al., 2010). Hence, the occurrence of short chain PFCs in fresh bodies must be studied.

The level of PFCs and their exchange/distribution with the sediment pool in large drinking water resources/lakes are of fundamental significance for establishing drinking water standards. As an important component in natural waters, sediment serves as an important sink for hydrophobic organic contaminants (Lebeuf and Nunes, 2005). However, being both hydrophobic and hydrophilic, PFOS/PFOA behaves differently from typical hydrophobic chemicals in terms of the distribution in water and sediment. Higgins and Luthy reported that the sorption of perfluoroalkyl sulfonic acids (PFSAs) and perfluoroalkyl carboxylic acids (PFCAs) increased with the chain length (Higgins and Luthy, 2006). Recently, Pan et al. found that high salinity and ionic strength enhanced the uptake of PFOS on sediments, making estuaries an important sink for PFOS during its transport from land to the ocean (Pan and You, 2010; You et al., 2010). Most studies on PFCs in sediments have been focused on the oceans; little is known on their presence and distribution in large freshwater bodies (Ahrens et al., 2010a; Ahrens et al., 2010b; Ahrens et al., 2010c). Until now, it has not been clear whether sediment acts as an internal source reservoir or sinks to PFCs and how the dynamics are altered, thereby affecting PFCs in freshwater systems under various natural environmental conditions.

In this study, we surveyed the concentration levels in water and sediment on 7 types of PFCs at 16 stations throughout Lake Taihu. The influence of the chain length and the functional groups on the partitioning of different PFCs on the sediment was studied. Partition coefficient $K_{\mathrm{d}}$ was used to interpret the field survey observations. Using the current concentration levels, the potential health risks of PFOA/PFOS were assessed. The study aimed to provide baseline data for developing drinking water standards for PFCs in freshwater with special attention being paid to the buffering reservoir of the sediment.

\section{Experimental}

\subsection{Chemicals}

Perfluorooctane sulfonate (PFOS, potassium salt) and other PFCs were provided by Tokyo Kasei Kogyo (Japan), and their properties are listed in Table S1 of the supporting information (SI). Sodium perfluoro- $[1,2,3,4]]^{13} \mathrm{C}$-octaneslufonate (MPFOS) $(99 \%, 50 \mu \mathrm{g} \mathrm{mL}$ solution in methanol) was purchased from Wellington Laboratories Inc. (Canada). HPLC-grade methanol was purchased from Fisher Chemical (USA). Milli-Q water was produced by Millipore (Boston, USA). Other chemicals were of analytical reagent grade.

\subsection{Water and sediment sampling}

Samples of water and sediment were collected in May 2010 from Lake Taihu, China. The sampling locations were distributed throughout the lake (Fig. 1). Water samples were collected using a polypropylene (PP) bucket pre-cleaned with methanol and Milli-Q water at a depth of approximately $0.5 \mathrm{~m}$ below the surface of the water. Parameters, including $\mathrm{pH}$, temperature (T), dissolved oxygen (DO), conductivity and salinity, were measured (Table S2 of the SI) in situ using a water quality survey instrument (556 Handheld Multiparameter, YSI, USA). Samples were stored in PP bottles at $4 \pm 2{ }^{\circ} \mathrm{C}$ and brought to the lab before extraction.

Sediment samples were collected with a column sediment sampler (Beeker) and were divided into several sections according to the sampling depth at intervals of $5 \mathrm{~cm}$ (from sediment surface to deeplayer). They were kept in PP bags at $4 \pm 2{ }^{\circ} \mathrm{C}$ before analysis. The sediment samples were freeze-dried and passed through 80 mesh sieves before being used for the experiment.

\subsection{Sample treatment and analysis}

Water samples were pre-treated according to the previously reported method (Ahrens et al., 2010b). Samples were filtered through $0.22 \mu \mathrm{m}$ fiberglass filters (GF/F) to remove sediments and biota before extraction. All samples were extracted by solid phase extraction (SPE) with Oasis WAX cartridges (Waters, $6 \mathrm{cc}, 150 \mathrm{mg}, 30 \mu \mathrm{m}$ ). The SPE cartridges were first preconditioned by passing $4 \mathrm{~mL}$ of ammonium hydroxide in methanol, $4 \mathrm{~mL}$ of methanol, and then $4 \mathrm{~mL}$ of Milli-Q water. Before loading onto the cartridge, the samples were spiked with $1 \mathrm{ng}$ internal standard (IS) of PFOS. The cartridges were rinsed with $4 \mathrm{~mL}$ of $25 \mathrm{mM}$ ammonium acetate buffer (pH 4) in Milli-Q water and dried by centrifugation at $3000 \mathrm{rpm}$ for $20 \mathrm{~min}$. The elution was performed with $4 \mathrm{~mL}$ of methanol and $4 \mathrm{~mL}$ of $0.1 \%$ ammonium hydroxide, then reduced to $1 \mathrm{~mL}$ under a nitrogen stream, and analyzed using ultra performance liquid chromatography-tandem mass spectrometry (UPLC-MS/MS).

Sediment samples were extracted using the previously reported method (Ahrens et al., 2009b; Deng et al., 2011). Briefly, $2 \mathrm{~g}$ of dried sediment was extracted by adding $2 \mathrm{~mL}$ of $200 \mathrm{mM} \mathrm{NaOH}$ and stirred for $30 \mathrm{~min}$ at $150 \mathrm{rpm}$. A volume of $20 \mathrm{~mL}$ pure methanol and $20 \mu \mathrm{L}$ IS of PFOS were added into the mixture with stirring for $30 \mathrm{~min}$ at $150 \mathrm{rpm}$. A volume of $0.2 \mathrm{~mL}$ of $2 \mathrm{M} \mathrm{HCl}$ was added to the extract, which was then centrifuged at $3000 \mathrm{rpm}$ for $20 \mathrm{~min}$. A volume of $50 \mu \mathrm{L}$ acetic acid was added to the supernatant and the mixture was shaken for $1 \mathrm{~min}$ and centrifuged at 10,000 rpm for $20 \mathrm{~min}$. The final supernatant was collected for analysis by UPLC-MS/MS. All samples were analyzed in duplicate.

\subsection{PFCs determination and quality assurance}

Ultra performance liquid chromatography-tandem mass spectrometry (UPLC-MS/MS) was used to determine the concentrations of PFCs. The UPLC system (Waters Corp., USA) was equipped with an ACQUITY UPLC BEH C18 column $(2.1 \mathrm{~mm} \times 50 \mathrm{~mm}$, I.D., particle size $1.7 \mu \mathrm{m}$, Waters Corp., USA). The MS system was a Quattro Premier XE tandem quadrupole mass spectrometer (Waters Corp., USA) equipped with an electrospray ionization source. The analytical procedures were reported previously (Ahrens et al., 2009b; Zhou et al., 2010; Zhou et al., 2013; Zhuo et al., 2011). The mobile phase consisted of a binary mixture of solvent $A$ ( $2 \mathrm{mmol} \mathrm{L}^{-1}$ ammonium acetate in $100 \%$ metha$\mathrm{nol})$ and $\mathrm{B}(2 \mathrm{mmol} \mathrm{L}-1$ ammonium acetate in 5\% methanol) at a flow rate of $0.3 \mathrm{~mL} \mathrm{~min}^{-1}$. The gradient, which is listed in Table S3 of the SI started with $25 \% \mathrm{~A}$ and $75 \% \mathrm{~B}$ and linearly ramped to $85 \% \mathrm{~A}$ and $15 \%$ B for $5 \mathrm{~min}$, then ramped to $25 \% \mathrm{~A}$ and $75 \%$ B for $2 \mathrm{~min}$. The column was allowed to equilibrate for $3 \mathrm{~min}$, and the total running time was $10 \mathrm{~min}$. The injection volume was $10 \mu \mathrm{L}$. The tandem MS analysis was conducted using the multiple reactions monitoring (MRM) mode, and the cone voltage and collision energy were $30 \mathrm{~V}$ and $11 \mathrm{~V}$, respectively. The calibration conditions are specified in Table S4 of the SI.

Spike and recovery experiments were performed to determine the precision and accuracy of the extraction and the analytical procedure. The recovery of PFOS ranged from $80 \%$ to $112 \%$ for water samples and from $74 \%$ to $102 \%$ for sediment samples. The instrument detection limit was $1 \mathrm{ng} \mathrm{L}^{-1}$. 


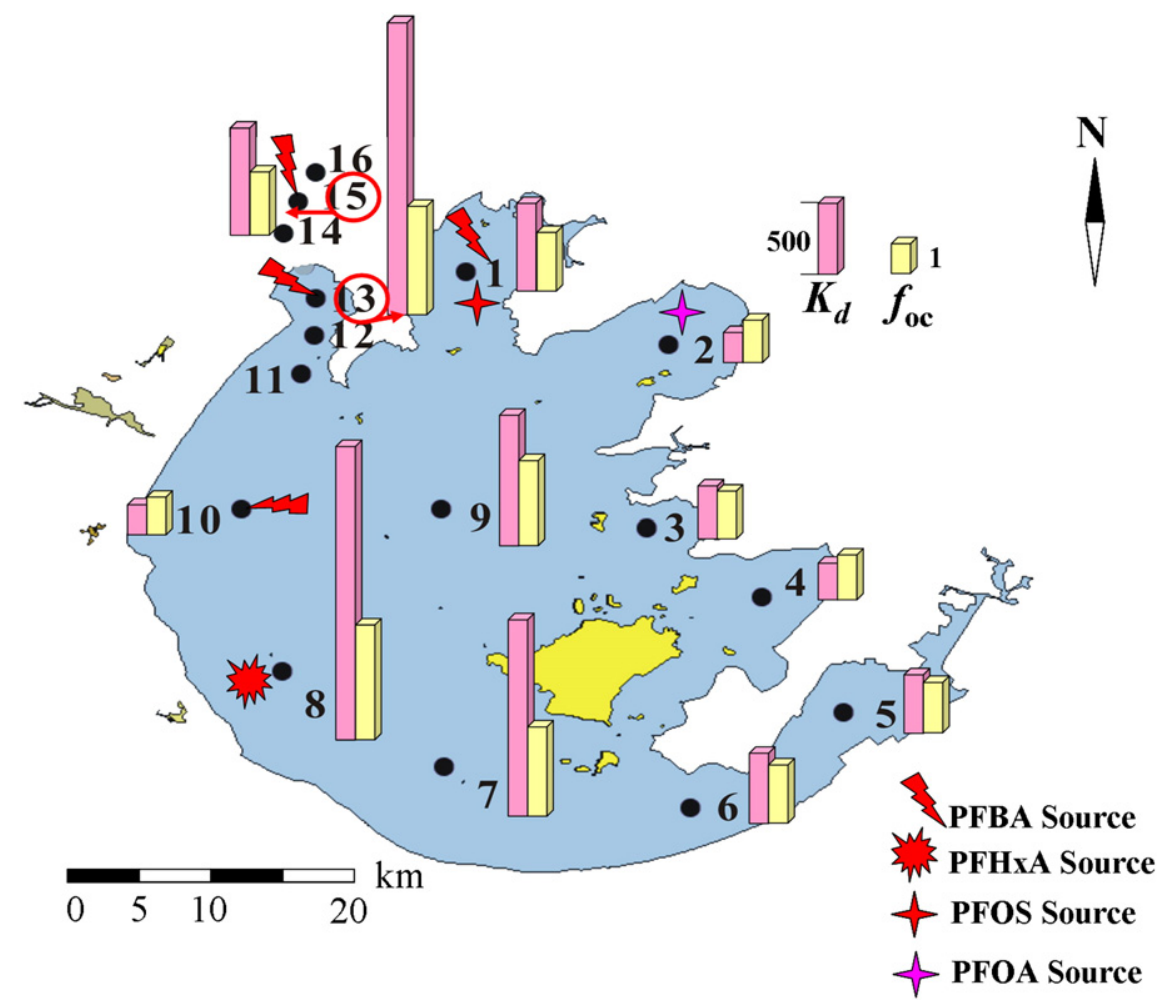

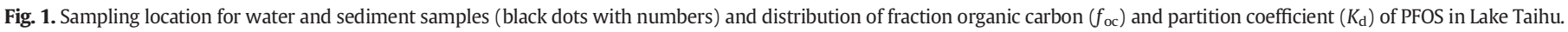

\section{Results and discussion}

\subsection{Occurrence of PFCs in water}

The concentrations of different forms of PFCs in water are presented in Table S5 of the SI, and the PFC distributions at various locations are shown in Fig. 2. Eleven target PFCs were studied, but only seven PFCs, heptafluorobutyric acid (PFBA), undecafluorohexanoic acid (PFHxA), perfluoroheptanoic acid (PFHeA), PFOA, perfluorononanoic acid (PFNA), potassium perfluorobutanesulfonate (PFBS) and PFOS, were detectable in all water samples. The highest $\sum$ PFC concentration (299 ng L $\mathrm{L}^{-1}$ ) was observed in location 1 from Meiliang Bay, followed by location 2 from Gonghu Bay. PFCAs accounted for approximately $85 \%$ of the $\sum$ PFCs in water. PFOA was predominated among all target PFCAs detected, with concentrations ranging from $49 \mathrm{ng} \mathrm{L}^{-1}$ (location 7) to $136 \mathrm{ng} \mathrm{L}^{-1}$ (location 2). PFBA concentrations were the second highest, from $22 \mathrm{ng} \mathrm{L}^{-1}$ (location 5) to $129 \mathrm{ng} \mathrm{L}^{-1}$ at an estuary mouth (location 15). The concentration of PFOS in the water samples ranged from $9 \mathrm{ng} \mathrm{L}^{-1}$ (location 7) to $29 \mathrm{ng} \mathrm{L}^{-1}$.

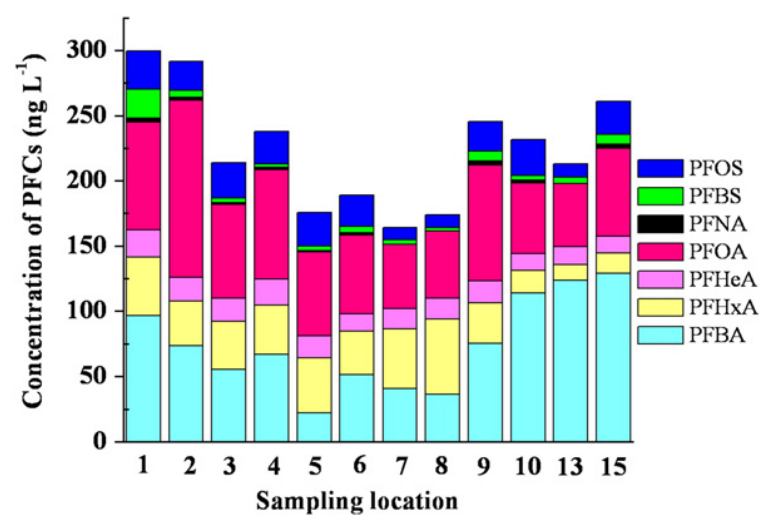

Fig. 2. Spatial distribution of all PFCs in water from Lake Taihu.
The $\sum$ PFC concentration (867 $\mathrm{ng} \mathrm{L}^{-1}$ ) in a lake in Korea (Rostkowski et al., 2006) was much higher than the result of this study. However, the $\sum$ PFC concentration (299 $\mathrm{ng} \mathrm{L}^{-1}$ ) in Lake Taihu was approximately 10 times higher than the levels in some European rivers such as River Elbe (26.4 $\mathrm{ng} \mathrm{L}^{-1}$ ) (Ahrens et al., 2009a). Yang et al. (2011) reported that PFOS was the main component of PFCs in water, with the highest level of $394 \mathrm{ng} \mathrm{\textrm {L } ^ { - 1 }}$ in Lake Taihu. In contrast to their result, our data indicated that PFOA (136 ng L ${ }^{-1}$ ) predominated over PFOS (29.2 $\mathrm{ng} \mathrm{L}^{-1}$ ) in the Lake Taihu water. The difference may be due to the different sampling season (summer in 2010 vs. winter in 2009). Seasonal change may be significant because the algal blooms in the summer in Lake Taihu may largely affect the distribution of different forms of PFCs. PFOS and PFOA may be biosorbed to a different extent by the algae cells during algal blooms. The algal bloom may play a unique role during the sedimentation of PFOS. However, little is known on this issue, which will be an interesting topic for our future studies.

Compared to the only available water standards in the USA, such as US EPA standards of $0.2 \mu \mathrm{g} \mathrm{L} \mathrm{L}^{-1}$ for PFOS and $0.4 \mu \mathrm{g} \mathrm{L}^{-1}$ for PFOA in drinking water, Lake Taihu water is currently below the risk level based on our data (PFOS $<0.029 \mu \mathrm{g} \mathrm{L}^{-1}$, PFOA $<0.136 \mu \mathrm{g} \mathrm{L}^{-1}$ ). However, according to the previous report $\left(0.394 \mu \mathrm{g} \mathrm{L}^{-1}\right.$ for PFOS and $0.037 \mu \mathrm{g} \mathrm{L}^{-1}$ for PFOA) (Yang et al., 2011), Lake Taihu already has double the critical risk point for PFOS. Even if the current levels in water are below the standards, the sediment reservoir may change these dynamics under different conditions (e.g., seasons). More importantly, bioaccumulation and non-degradability of PFOS/PFOA must be taken into consideration for the health impact because "safe water" may be not safe after human consumption of the aquatic products for a certain period of time.

\subsection{Risk assessment of PFOS and PFOA}

Risk assessment to humans is essential for drinking water standards because drinking water is one of the exposure pathways of PFCs for human or animals. We estimated the potential health risk of PFOS and 
Table 1

Values of emergent times (ETs).

\begin{tabular}{|c|c|c|c|c|c|c|c|}
\hline Species & $\mathrm{C}_{\text {water }}\left(\mathrm{ng} \mathrm{L}^{-1}\right)$ & BAF $_{\text {fish }}$ (Fujii et al., 2007) & $\mathrm{C}_{\text {fish }}\left(\mathrm{ng} \mathrm{g}^{-1}\right)$ & $\begin{array}{l}\text { Mass }\left(\mathrm{g} \mathrm{d}^{-1} \text { ) }\right. \\
\text { (Gulkowska et al., 2006) }\end{array}$ & $\begin{array}{l}\text { W (kg) } \\
\text { (Gulkowska et al., 2006) }\end{array}$ & $\begin{array}{l}\mathrm{RD}_{\text {fish-consum }}\left(\mathrm{mg} \mathrm{kg}^{-1}\right) \\
\text { (Hu and Zhong, 2006) }\end{array}$ & ET (years) \\
\hline \multirow[t]{6}{*}{ PFOS } & 8.9 & 6615 & 58.9 & 77 & 60 & 250 & 908 \\
\hline & 29.2 & 46620 & 1361 & 287 & 60 & 250 & 10.5 \\
\hline & 8.9 & 6615 & 58.9 & 77 & 60 & 100 & 363 \\
\hline & 29.2 & 46620 & 1361 & 287 & 60 & 100 & 4.2 \\
\hline & 8.9 & 6615 & 58.9 & 77 & 60 & 10 & 36 \\
\hline & 29.2 & 46620 & 1361 & 287 & 60 & 10 & 0.42 \\
\hline \multirow[t]{4}{*}{ PFOA } & 49.2 & 184 & 9 & 77 & 60 & 500 & 5903 \\
\hline & 136 & 184 & 25 & 287 & 60 & 500 & 573 \\
\hline & 49.2 & 184 & 9 & 77 & 60 & 100 & 2361 \\
\hline & 136 & 184 & 25 & 287 & 60 & 100 & 229 \\
\hline
\end{tabular}

PFOA by water intake for animals/humans through reference dose (RD) by evaluating the hazard ratio (HR) (Gulkowska et al., 2006).

$\mathrm{HR}=\mathrm{ADC} / \mathrm{RD}$

where ADC ( $\mu \mathrm{g} \mathrm{kg}^{-1} \mathrm{~d}^{-1}$ ) represents the estimated average daily consumptions.

When the intake of drinking water was considered alone,

$$
\begin{gathered}
\mathrm{HR}_{\text {water }}=\mathrm{ADC}_{\text {water }} / \mathrm{RD}_{\text {water }} \\
\mathrm{ADC}_{\text {water }}=\frac{\mathrm{C}_{\text {water }} \times \mathrm{V}_{\text {water }} \times 10^{-3}}{\mathrm{~W}}
\end{gathered}
$$

where $C_{\text {water }}\left(\mathrm{ng} \mathrm{L}^{-1}\right)$ is the concentration of PFOS/PFOA in water. $\mathrm{V}_{\text {water }}$ $(\mathrm{L})$ is the drinking water volume for an adult every day. $\mathrm{W}(\mathrm{kg})$ is the average weight of an adult. $R D_{\text {water }}$ is $0.025 \mu \mathrm{gg}^{-1} \mathrm{~d}^{-1}$ for PFOS and $0.333 \mu \mathrm{g} \mathrm{kg}^{-1} \mathrm{~d}^{-1}$ for PFOA based on rat chronic carcinogenicity ( $\mu \mathrm{g} \mathrm{kg}^{-1} \mathrm{~d}^{-1}$ ) (Gulkowska et al., 2006).

We assume the adult average weight to be $60 \mathrm{~kg}$ and that $2 \mathrm{~L}$ of water is consumed each day (Gulkowska et al., 2006). Based on the current concentration levels of $8.9-29.2 \mathrm{ng} \mathrm{L}^{-1}$ for PFOS and 49.2-136 ng $\mathrm{L}^{-1}$ for PFOA in Lake Taihu, the $\mathrm{HR}_{\text {water }}$ ranged from 0.011 to 0.039 for PFOS and from 0.0049 to 0.014 for PFOA through the intake of drinking water only. When $\mathrm{HR}_{\text {water }}$ is less than one, the level of PFCs would not result in emerging health effects to animals/ humans (Loi et al., 2011). Our result suggested that the current concentration levels of PFOS and PFOA in Lake Taihu should not cause immediate health impact through the intake of the water alone (note that the lake water is treated by water works before being supplied to the tap).

However, the scenario can be greatly altered when aquatic products consumption is taken into consideration because some fish may have very high bioaccumulation factor (BAF). For the freshwater fish in Lake Biwa, $\mathrm{BAF}_{\text {fish }}$ ranged from 6615 to 46620 for PFOS and 184 for PFOA (Fujii et al., 2007). Supposing that the fish species in Lake Taihu have similar $\mathrm{BAF}_{\text {fish, }}$, based on the current Lake Taihu water concentration $C_{\text {water }}$ (8.9-29.2 $\mathrm{ng} \mathrm{L}^{-1}$ for PFOS and 49.2-136 ng L ${ }^{-1}$ for PFOA), the concentrations of PFOS/PFOA in fish $\left(\mathrm{C}_{\text {fish }}, \mathrm{ng} \mathrm{g}^{-1}\right)$ may range between 58.9 and $1361 \mathrm{ng} \mathrm{g}^{-1}$ for PFOS and 9 and $25 \mathrm{ng} \mathrm{g}^{-1}$ for $\operatorname{PFOA}\left(\mathrm{C}_{\text {fish }}=\mathrm{C}_{\text {water }} \times \mathrm{BAF}_{\text {fish }}\right)$.

Supposing a mass of $182 \pm 105 \mathrm{~g}$ of fish was taken for an adult each day (Gulkowska et al., 2006), the concentration of PFOS/PFOA in the animal/human body $\left(\mathrm{C}_{\text {body }}, \mathrm{mg} \mathrm{kg}^{-1}\right)$ can be obtained from Eq. (3).

$\mathrm{C}_{\text {body }}\left(\mathrm{mg} \mathrm{kg}^{-1}\right)=\frac{\mathrm{C}_{\text {fish }}\left(\mathrm{mg} \mathrm{kg}^{-1}\right) \times \operatorname{Mass}\left(\mathrm{gd}^{-1}\right) \times \mathrm{ET}(\text { years }) \times 365 \times 10^{-6}}{\mathrm{~W}(\mathrm{~kg})}$

where Mass $\left(\mathrm{g} \mathrm{d}^{-1}\right)$ is the amount of fish eaten by an adult every day (77-287 g) (Gulkowska et al., 2006). Emergent time (ET, years) is the time when an emerging health impact in the animal/human occurs after fish consumption.
The potential health risks emerge when $C_{\text {body }}$ is higher than the $\mathrm{RD}_{\text {fish-consum. }}$. Here, the median lethal dosage $\left(\mathrm{LD}_{50}\right)$ of rats (250 $\mathrm{mg} \mathrm{kg}^{-1}$ for PFOS and $500 \mathrm{mg} \mathrm{kg}^{-1}$ for PFOA (Hu and Zhong, 2006)), liver toxicity in mice ( $100 \mathrm{mg} \mathrm{kg}^{-1}$ for PFOS/PFOA) and toxicity of embryonic development ( $10 \mathrm{mg} \mathrm{kg}^{-1}$ for PFOS) were considered in the reference dosage $\left(\mathrm{RD}_{\text {fish-consum }}\right)$ and were adopted as emerging toxicity to animals/human.

Based on the abovementioned method, the emergent time (ET, years) was calculated and listed in Table 1. The ET was 10.5-908 years for PFOS and 573-5903 years for PFOA when the $\mathrm{LD}_{50}$ of rats was considered alone. The ET was 4.2-363 years for PFOS and 229-2361 years for PFOA when liver toxicity in mice was considered alone. The ET was 0.42-36 years for PFOS when the toxicity of embryonic development in mice was considered alone. The ET of PFOA was much longer than its arithmetic mean half-lives in human serum (3.8 years (Olsen et al., 2007)), suggesting the safety of the current PFOA level in the lake. However, the 4.2 years and 0.42 years of PFOS were less than its arithmetic mean halflives in human serum (5.4 years (Olsen et al., 2007)). A potential health impact for humans could occur after half a year consumption of aquatic products with high bioaccumulation factors of PFOS for animals or humans. The current PFOS concentrations may cause potential threats to human or animals when bioaccumulation is taken into consideration. Hence, the development of drinking water standards for PFOS/PFOA should not only rely on their current concentration levels in the water but also the bioaccumulation of aquatic products.

\subsection{Sources of PFCS}

Some researchers applied the ratio of PFCs to PFOA to identify the potential source of the PFCs (Simcik and Dorweiler, 2005; Wang et al., 2012). The PFBA/PFOA ratios in this study were mostly less than 1.0, but some samples were greater than 1.0 , such as L1 (1.17) from Meiliang Bay, L10 (2.10) and L13 (2.52) from Zhushan Bay and L15 (1.92) from the estuary of the lake (Table 2). The results exhibited higher PFBA concentrations than PFOA, which is indicative of potential

Table 2

Parameters for the sources of PFCs.

\begin{tabular}{lclrll}
\hline & \multicolumn{3}{c}{ Water samples $\left(\mathrm{ng} \mathrm{L}^{-1}\right)$} & \multicolumn{2}{l}{ Source indicator } \\
\hline Location & PFBA & PFHxA & PFOA & PFBA/PFOA & PFHxA/PFOA \\
1 & 96.6 & 44.8 & 82.7 & $\mathbf{1 . 1 7}$ & 0.54 \\
2 & 73.4 & 34.1 & 136.1 & 0.54 & 0.25 \\
3 & 55.3 & 36.9 & 71.5 & 0.77 & 0.52 \\
4 & 66.7 & 37.7 & 84.1 & 0.79 & 0.45 \\
5 & 21.9 & 42.2 & 64.2 & 0.34 & 0.66 \\
6 & 51.1 & 33.4 & 60.4 & 0.85 & 0.55 \\
7 & 40.7 & 45.7 & 49.2 & 0.83 & 0.93 \\
8 & 36.1 & 57.5 & 51.6 & 0.70 & $\mathbf{1 . 1 1}$ \\
9 & 75.5 & 30.6 & 89.1 & 0.85 & 0.34 \\
10 & 113.8 & 17.4 & 54.4 & $\mathbf{2 . 1 0}$ & 0.32 \\
13 & 123.6 & 12.2 & 49.1 & $\mathbf{2 . 5 2}$ & 0.25 \\
15 & 129.3 & 15.5 & 67.4 & $\mathbf{1 . 9 2}$ & 0.23 \\
\hline
\end{tabular}


point sources of PFBA (Fig. 1). Similarly, the ratio of PFHxA/PFOA from L8 was 1.11, which was higher than 1.0 and indicated the potential point source of PFHxA. The abovementioned locations are close to industrial areas, especially L1, which is close to manufacturers of paints and plastic anticorrosion products (Zhang et al., 2010). Fluorinated chemicals are either the raw materials or the end products of these manufacturers. The highest level of PFOA (136 ng L ${ }^{-1}$, Table S5 of SI) was found in the water around location 2 from Gonghu Bay, where plants producing polytetrafluoroethylene were located. The contamination of PFCs can be attributed to the direct input from industrial activities or indirect discharge of effluent from municipal waste water treatment plants.

\subsection{Buffering reservoir of PFOS in the sediment and partition of PFCS}

The vertical profile of PFCs in the sediment of different sampling location is shown in Fig. 3, and the concentration levels in the sediment samples $(0-5 \mathrm{~cm})$ are summarized in Table S6 of the SI. The distribution of PFCs in the sediment showed a very different pattern from that in the water. The short chain PFCAs, such as PFBA, PFHxA and PFHeA, were not detectable, and only three PFCs, including PFBS, PFOS and PFOA, were detectable in all the sediments. The highest concentration of $\sum$ PFCs was $35 \mathrm{ng} \mathrm{g}^{-1}(\mathrm{dw})$ in the surface sediment. PFOS accounted for $55 \%-96 \%$ of the $\sum$ PFCs, ranging from $4.8 \mathrm{ng} \mathrm{g}^{-1}$ (dw) to $21.7 \mathrm{ng} \mathrm{g}^{-1}$ (dw). The highest concentrations of PFOA and PFBS in the sediment were $11.4 \mathrm{ng} \mathrm{g}^{-1} \mathrm{dw}$ (location 1 ) and $4.3 \mathrm{ng} \mathrm{g}^{-1} \mathrm{dw}$ (location 1 ), respectively. The highest concentrations were found at a depth of $5-10 \mathrm{~cm}$ in all sediments, except for location 9 in the center of Lake Taihu. When the depth was deeper than $10 \mathrm{~cm}$, the concentrations of both the $\sum$ PFCs and the individual PFCs decreased with the depth, suggesting a sedimentation process.

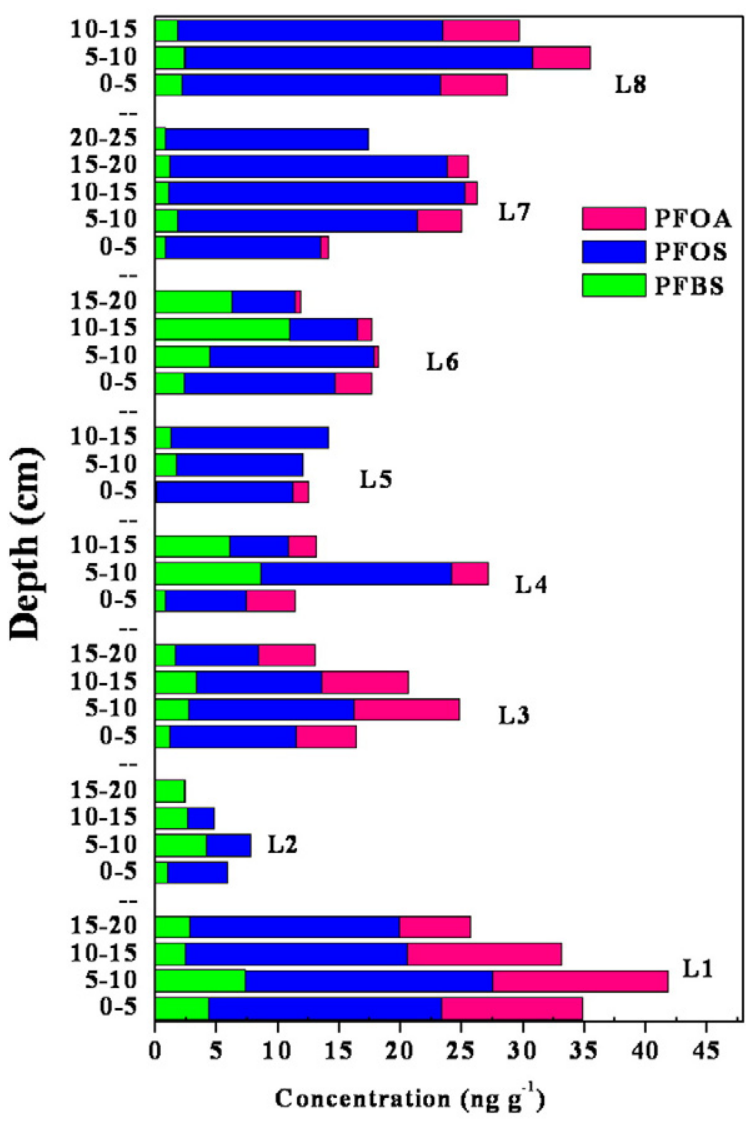

The sedimented PFOS may serve as an internal reservoir that may later be released back to the water column when conditions are changed, such as re-suspension of the sediment and diffusion as a result of the dilution of water. Even if the industrial input of PFOS/PFOA is reduced, the water level of PFOS may be buffered to some extent due to the internal loads in the sediment. Further studies are needed to assess this effect.

The partition of PFOS, PFOA and PFBS between sediment and water was described with the empirical partition coefficient $\left(K_{\mathrm{d}}\right)$, assuming equilibrium conditions at the time of the sampling. The $K_{\mathrm{d}}$ values ranged from 211 to $2090 \mathrm{~L} \mathrm{~kg}^{-1}$ for PFOS, 0 to $137 \mathrm{~L} \mathrm{~kg}^{-1}$ for PFOA and 92 to $478 \mathrm{~L} \mathrm{~kg}^{-1}$ for PFBS (Fig. 4). This is comparable with our previous studies, where the $K_{\mathrm{d}}$ values were $200-4050 \mathrm{~L} \mathrm{~kg}^{-1}$ for PFOS and 150-350 $\mathrm{L} \mathrm{kg}^{-1}$ for PFOA, considering the differences in the concentration levels, water quality and properties of the sediments (Zhou et al., 2010). The $K_{d}$ values of PFOS were generally much higher than PFOA and PFBS, suggesting that PFOS had the highest affinity for sediments, which agreed with our sediment profile field survey (Fig. 3, PFOS was 4.8-21.7 $\mathrm{ng} \mathrm{g}^{-1}$, PFOA was $<0.01-11.4 \mathrm{ng} \mathrm{g}^{-1}$, PFBS was $0.7-4.3 \mathrm{ng} \mathrm{g}$ $\left.{ }^{-1}\right)$. The $K_{\mathrm{d}}$ values of PFOA were much lower than those of PFOS, which explained why PFOA was favorable in the water and PFOS predominated in the sediments.

The relationship between $K_{\mathrm{d}}$ and the organic carbon fraction $\left(f_{\text {oc }}\right)$ was examined in Fig. 4. A positive correlation between $K_{\mathrm{d}}$ and $f_{\text {oc }}$ was found for PFOS $\left(\mathrm{R}^{2}=0.961\right)$, but not for PFOA and PFBS. When the $K_{d}$ and $f_{\text {oc }}$ of PFOS were put into the map of the lake (Fig. 1), an interesting pattern was observed. The $f_{\text {oc }}$ of the west half of the lake was generally higher than the east half of the lake. Accordingly, the $K_{\mathrm{d}}$ values showed the same pattern as that of the $f_{\text {oc }}$ (Fig. 1). The north-west of the lake suffers the most from harmful algal bloom, especially during the summer, due to the accumulation effect driven by the southeast wind. The correlation between $K_{\mathrm{d}}$ and $f_{\text {oc }}$ (Fig. 4 ) and the distribution map

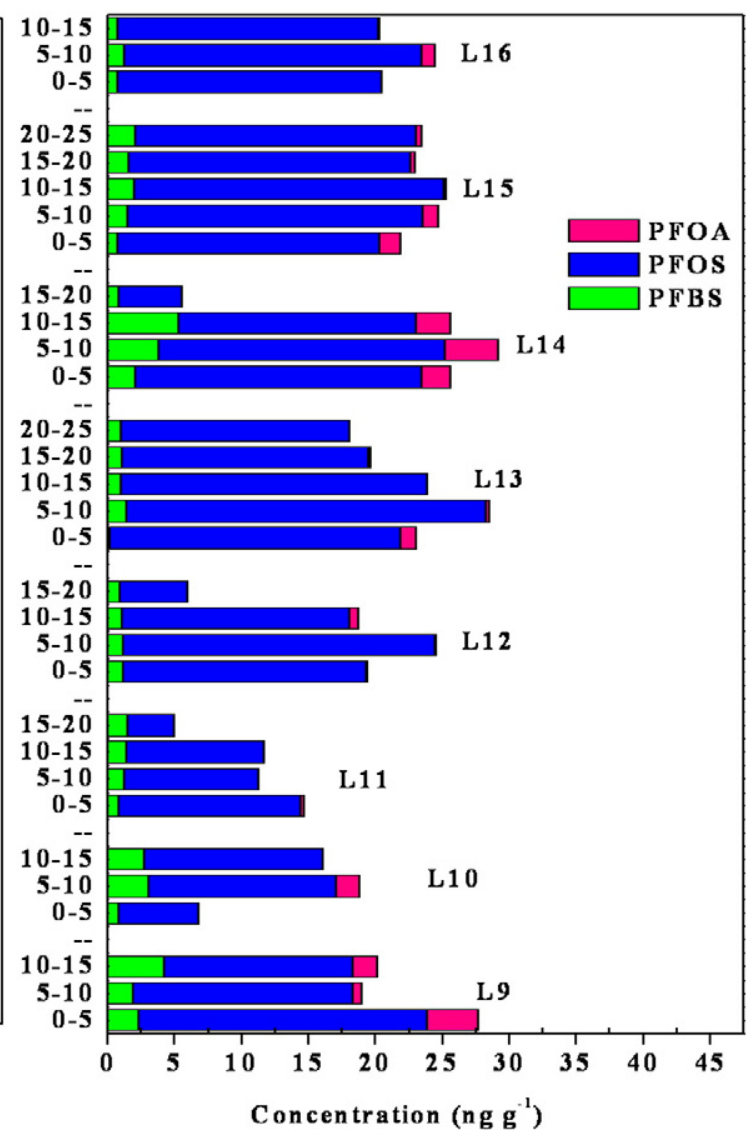

Fig. 3. Vertical profile of PFCs in sediment ( $\mathrm{ng} \mathrm{g}^{-1} \mathrm{dw}$ ) from sixteen sampling locations in Lake Taihu. 


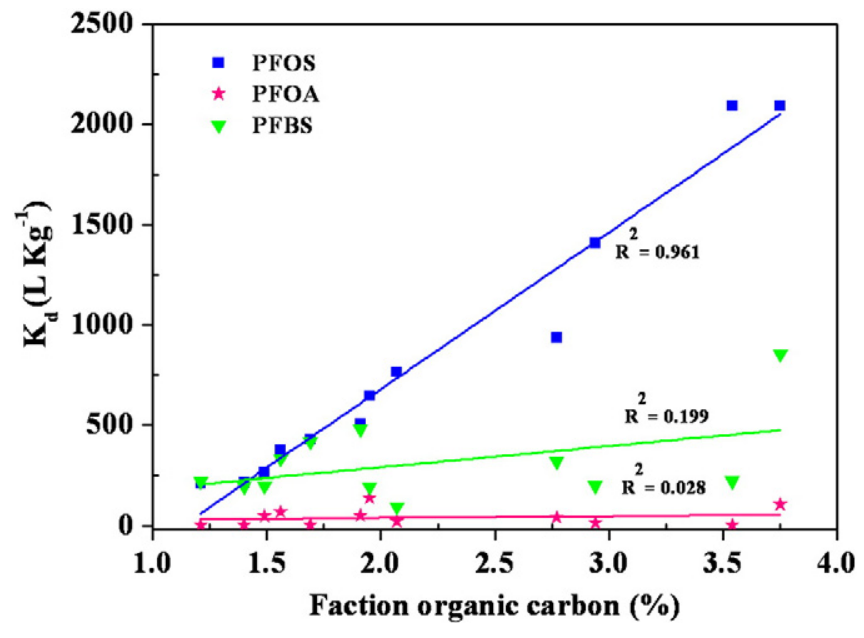

Fig. 4. Relationship between fraction organic carbon $\left(f_{\text {oc }}\right)$ and partition coefficient $\left(K_{\mathrm{d}}\right)$.

of $K_{\mathrm{d}}$ and $f_{\mathrm{oc}}$ in the lake (Fig. 1 ) suggested that the organic carbon content dominated the distribution of PFOS in the sediment, which was consistent with earlier reported works where hydrophobic interactions played a strong role in the adsorption of long chain PFCs in the sediments (Jeon et al., 2011; Pan et al., 2009).

\subsection{Relationship between the partition and molecular structure}

Previous reports on PFCs focused on the composition and concentration levels (Qiu et al., 2010; Yang et al., 2011) and little was known about the relationship between the molecular structures of PFCs and their partition behavior. Here, we analyzed how the functional groups and the chain lengths of different PFCs affect the partitioning/sorption processes.

The level of PFCAs with the same functional groups but different chain lengths in water decreased with increasing chain length, with the exception of PFOA (Fig. 2). This is likely due to the higher solubility of short chain PFCAs compared to the long chain counterparts, which are more hydrophobic (Table S1 of the SI). The exception of PFOA might be due to its wider use compared to other PFCAs in the industries in the sampling area. PFOS and PFOA have the same C-F chain length (C8) but different functional groups, and the PFOS concentration in water is much lower than the PFOA concentration, possibly due to the greater hydrophobic nature of the sulfonate group (Deng et al., 2011; Fujii et al., 2007). A similar trend was observed between PFBS and PFBA (C4). Higher levels of PFBA than PFBS were detected in the water, which is more hydrophobic and less soluble in water. The short chain substances and compounds with carboxylic groups resulted in higher solubility and consequently higher concentrations in the water bodies.

The organic carbon normalized partition coefficient $\left(\log K_{\mathrm{oc}}, K_{\mathrm{oc}}=\right.$ $K_{d} \times 100 / f_{\text {oc }}$ ), which excludes the influence of the organic carbon content on the different distribution patterns, was employed to qualify the relationship between the partitioning and the molecular structure. The average $\log K_{\mathrm{oc}}$ values of PFOS, PFOA and PFBS were $4.58 \pm 0.05$, $3.23 \pm 0.13$ and $2.56 \pm 0.31 \mathrm{~L} \mathrm{~kg}^{-1}$, respectively. Our $\log K_{\mathrm{oc}}$ values were mostly in line with the previously reported data (Ahrens et al., 2010b; Ahrens et al., 2009b; Higgins and Luthy, 2006; Yang et al., 2011). The variation may be partially related to the different characteristics of the sediments/particles and the aquatic environment. It may also due to the fact that $K_{\mathrm{oc}}$ is empirically defined, which does not account for the effects of $\mathrm{pH}$, ionic strength and salinity. Some authors showed an increasing sorption of PFCs with decreasing $\mathrm{pH}$ of approximately $0.37 \log$ units per pH unit (Higgins and Luthy, 2006). Pan and You indicated that salinity had a strong influence on the $\log K_{\mathrm{oc}}$, with a contribution of $0.22 \log$ units for $\log K_{\mathrm{oc}}$ per unit salinity (\%)
(Pan and You, 2010). In this study, the influence of salinity and pH on PFCs partitioning may be not significant because they were similar in all sample locations (Table $\mathrm{S} 2$ of the $\mathrm{SI}$ ).

The $\log K_{\mathrm{oc}}$ of PFOS was higher than PFBS and PFOA by 2.02 and 1.35 $\log$ units, respectively. For the same functional groups but different chain lengths, $K_{\mathrm{oc}}$ increased by $0.51 \log$ units for each additional $\mathrm{CF}_{2}$ moiety from PFBS to PFOS. The chain length and functional groups influenced $K_{\mathrm{oc}}$, which determined their distribution behavior. However, the influence of the chain length and functional groups on the $\log K_{\mathrm{oc}}$ varies. Higgins and Luthy (2006) concluded that each $\mathrm{CF}_{2}$ moiety contributed 0.5-0.6 $\log$ units to the $\log K_{\mathrm{oc}}$, and the sulfonate moiety contributed an additional $0.23 \log$ units compared to carboxylate analogs. Ahrens et al. (2010b) reported that the $\log K_{\mathrm{oc}}$ increased by $0.52-0.75 \log$ units for the PFCAs with each additional $\mathrm{CF}_{2}$ moiety, and $\log K_{\mathrm{oc}}$ for PFSAs was 0.71-0.76 log units higher than the PFCAs with the same chain length. The results further confirmed that PFOS had the highest affinity for the sediment, which may act as an internal buffering reservoir of PFOS.

\section{Conclusions}

This paper reported the first systematic study of seven types of PFCs in one of the largest drinking water sources in China. The total PFC concentration was 164 to $299 \mathrm{ng} \mathrm{L}^{-1}$ in water and 5.8 to $35 \mathrm{ng} \mathrm{g}^{-1}$ $(\mathrm{dw})$ in sediment. PFOS was largely associated with sediment, and sediment acted as an internal buffering reservoir of PFOS. There is no immediate health impact from the intake of the water alone; however, the consumption of fish may cause potential health influences for animals/ humans on a time scale of months to years. The relationship between the concentration, water-sediment distribution, bioaccumulation and toxicity is important for constructing water standards for PFCs.

\section{Acknowledgments}

The study was supported by the Chinese NSF funds (Grant No. 41103076, 21277161), Special Funds of the President of the CAS (No. 312B11YBLWYZJ2011001), and the Youth Innovation Promotion Association (29QNCX2012005) of CAS. ZHOU Q acknowledges the support of the K.C. Wong Education Foundation. We thank Dr. Tao Yu from the Chinese Academy of Environmental Sciences for his help with the sampling.

\section{Appendix A. Supplementary data}

Supplementary data to this article can be found online at http://dx. doi.org/10.1016/j.scitotenv.2013.11.100.

\section{References}

3M. Health consultation - perfluorochemical releases at the 3M-cottage grove facility. Atlanta, Georgia: U.S. Department of Health and Human Services; 2005.

Ahrens L, Felizeter S, Sturm R, Xie ZY, Ebinghaus R. Polyfluorinated compounds in waste water treatment plant effluents and surface waters along the River Elbe, Germany. Mar Pollut Bull 2009a;58:1326-33.

Ahrens L, Gerwinski W, Theobald N, Ebinghaus R. Sources of polyfluoroalkyl compounds in the North Sea, Baltic Sea and Norwegian Sea: evidence from their spatial distribution in surface water. Mar Pollut Bull 2010a;60:255-60.

Ahrens L, Taniyasu S, Yeung LWY, Yamashita N, Lam PKS, Ebinghaus R. Distribution of polyfluoroalkyl compounds in water, suspended particulate matter and sediment from Tokyo Bay, Japan. Chemosphere 2010b;79:266-72.

Ahrens L, Xie ZY, Ebinghaus R. Distribution of perfluoroalkyl compounds in seawater from Northern Europe, Atlantic Ocean, and Southern Ocean. Chemosphere 2010c;78: 1011-6.

Ahrens L, Yamashita N, Yeung LWY, Taniyasu S, Horii Y, Lam PKS, et al. Partitioning behavior of per- and polyfluoroalkyl compounds between pore water and sediment in two sediment cores from Tokyo Bay, Japan. Environ Sci Technol 2009b;43:6969-75.

Davies E. Damage limitation? Chemistry World Podcast: Chemistry World February 2012; 2012.

Deng SB, Zhou Q, Yu G, Huang J, Fan Q. Removal of perfluorooctanoate from surface water by polyaluminium chloride coagulation. Water Res 2011;45:1774-80. 
Fujii S, Polprasert C, Tanaka S, Lien NPH, Qiu Y. New POPs in the water environment: distribution, bioaccumulation and treatment of perfluorinated compounds - a review paper. J Water Supply Res Technol AQUA 2007;56:313-26.

Gulkowska A, Jiang QT, So MK, Taniyasu S, Lam PKS, Yamashita N. Persistent perfluorinated acids in seafood collected from two cities of China. Environ Sci Technol 2006;40:3736-41.

Higgins CP, Luthy RG. Sorption of perfluorinated surfactants on sediments. Environ Sci Technol 2006:40:7251-6.

Hu CL, Zhong LF. Progress of toxicological study on PFOS and PFOA. Chinese J Ind Med 2006;19:354-8.

Jeon J, Kannan K, Lim BJ, An KG, Kim SD. Effects of salinity and organic matter on the partitioning of perfluoroalkyl acid (PFAs) to clay particles. J Environ Monit 2011;13: 1803-10.

Lebeuf M, Nunes T. PCBs and OCPs in sediment cores from the lower St. Lawrence estuary, Canada: evidence of fluvial inputs and time lag in delivery to coring sites. Environ Sci Technol 2005;39:1470-8.

Loi EIH, Yeung LWY, Taniyasu S, Lam PKS, Kannan K, Yamashita N. Trophic magnification of poly- and perfluorinated compounds in a subtropical food web. Environ Sci Technol 2011:5506-13.

Mak YL, Taniyasu S, Yeung LWY, Lu GH, Jin L, Yang YL, et al. Perfluorinated compounds in tap water from china and several other countries. Environ Sci Technol 2009;43:4824-9.

Newsted JL, Jones PD, Coady K, Giesy JP. Avian toxicity reference values for perfluorooctane sulfonate. Environ Sci Technol 2005;39:9357-62.

Olsen GW, Burris JM, Ehresman DJ, Froehlich JW, Seacat AM, Butenhoff JL, et al. Half-life of serum elimination of perfluorooctanesulfonate, perfluorohexanesulfonate, and perfluorooctanoate in retired fluorochemical production workers. Environ Health Perspect 2007;115:1298-305.

Paerl HW, Huisman J. Climate - blooms like it hot. Science 2008;320:57-8.

Pan G, Jia CX, Zhao DY, You C, Chen H, Jiang GB. Effect of cationic and anionic surfactants on the sorption and desorption of perfluorooctane sulfonate (PFOS) on natural sediments. Environ Pollut 2009;157:325-30.

Pan G, You C. Sediment-water distribution of perfluorooctane sulfonate (PFOS) in Yangtze River Estuary. Environ Pollut 2010;158:1363-7.

Pan G, Zhang MM, Chen H, Zou H, Yan H. Removal of cyanobacterial blooms in Taihu Lake using local soils. I. Equilibrium and kinetic screening on the flocculation of Microcystis aeruginosa using commercially available clays and minerals. Environ Pollut 2006;141: 195-200.

Qiu Y, Jing H, Shi HC. Perfluorocarboxylic acids (PFCAs) and perfluoroalkyl sulfonates (PFASs) in surface and tap water around Lake Taihu in China. Front Environ Sci Eng Chin 2010;4:301-10.

Rosal R, Rodea-Palomares I, Boltes K, Fernandez-Pinas F, Leganes F, Petre A. Ecotoxicological assessment of surfactants in the aquatic environment: combined toxicity of docusate sodium with chlorinated pollutants. Chemosphere 2010;81:288-93.

Rostkowski P, Yamashita N, So IMK, Taniyasu S, Lam PKS, Falandysz J, et al. Perfluorinated compounds in streams of the Shihwa industrial zone and Lake Shihwa, South Korea. Environ Toxicol Chem 2006;25:2374-80.

Simcik MF, Dorweiler KJ. Ratio of perfluorochemical concentrations as a tracer of atmospheric deposition to surface waters. Environ Sci Technol 2005;39: 8678-83.

Wang TY, Khim JS, Chen CL, Naile JE, Lu YL, Kannan K, et al. Perfluorinated compounds in surface waters from Northern China: comparison to level of industrialization. Environ Int 2012;42:37-46.

Yamashita N, Kannan K, Taniyasu S, Horii Y, Petrick G, Gamo T. A global survey of perfluorinated acids in oceans. Mar Pollut Bull 2005;51:658-68.

Yang LP, Zhu LY, Liu ZT. Occurrence and partition of perfluorinated compounds in water and sediment from Liao River and Taihu Lake, China. Chemosphere 2011;83:806-14.

You C, Jia CX, Pan G. Effect of salinity and sediment characteristics on the sorption and desorption of perfluorooctane sulfonate at sediment-water interface. Environ Pollut 2010;158:1343-7.

Zhang XJ, Chen C, Ding JQ Hou AX, Li Y, Niu ZB, et al. The 2007 water crisis in Wuxi, China: analysis of the origin. J Hazard Mater 2010;182:130-5.

Zhou Q, Deng SB, Fan Q, Zhang QY, Yu G, Huang J. Sorption of perfluorooctane sulfonate and perfluorooctanoate on activated sludge. Chemosphere 2010;81:453-8.

Zhou Q Pan G, Zhang J. Effective sorption of perfluorooctane sulfonate (PFOS) on hexadecyltrimethylammonium bromide immobilized mesoporous $\mathrm{SiO}_{2}$ hollow sphere. Chemosphere 2013;90:2461-6.

Zhuo QF, Deng SB, Yang B, Huang J, Yu G. Efficient electrochemical oxidation of perfluorooctanoate using a Ti/SnO ${ }_{2}-\mathrm{Sb}-\mathrm{Bi}$ anode. Environ Sci Technol 2011;45: 2973-9. 